\title{
Accounting Record-Keeping Practices and Tax Compliance of Small and Medium Scale Enterprises in the Sekondi-Takoradi Metropolis of Ghana
}

\author{
Charles Ayariga \\ Faculty of Business Studies, Takoradi Technical University, PO Box 258, Takoradi, Ghana
}

\begin{abstract}
The purpose of the study was to investigate accounting record-keeping practices and tax compliance of Small and Medium Scale Enterprises (SMEs) in the Sekondi-Takoradi Metropolis (STM) of Ghana. The study adopted the concurrent triangulation mixed methods design. The study population was 895 owners/managers of SMEs and the two zonal heads of the Domestic Tax Revenue Division (DTRD). The sample size was 279. However, the study was able to collect accurate and complete data from 267 SME owners/managers and the two zonal heads of DTRD. Purposive and stratified random sampling procedures were used to select the participants and respondents, respectively. Questionnaire and interview guide were the instruments used. Mean, standard deviation, and linear multiple regression analysis were used to analyse the data. The findings revealed that SMEs in STM have poor accounting record-keeping culture; however, they exhibit a good attitude towards tax compliance. In all, the results show that an improvement in accounting record-keeping practice in the SME sector will lead to higher compliance with tax obligations ensuring the long term survival of the businesses. Based on the findings and conclusions, it was recommended to the zonal heads of DTRD that, as part of their education programmes, they should undertake record-keeping programmes to improve the quality of reporting by SMEs and other institutions to boost tax compliance.
\end{abstract}

Keywords: Accounting record-keeping practices, Motivational postures, Staff attitude, and Tax compliance DOI: $10.7176 /$ RJFA/11-2-04

Publication date: January $31^{\text {st }} 2020$

\section{Introduction}

Globally, the role of revenue in the development of a country is not less important than the role of oxygen for the existence of the human body. One of the most important policies for emerging nations is for them to mobilise their own internal resources to provide economic growth increasingly. This can be done through the implementation of effective tax policy (Witte \& Woodbury, 2015). Tax is a source of revenue for the government; hence, the need for small and medium scale enterprises (SMEs) to pay taxes (Bhattarai \& Koirala, 2017). However, due to poor tax compliance and record-keeping practices among SMEs in developing countries, governments in these countries are now finding it difficult to raise enough funds to spearhead development in their respective countries (Saani, 2017). Tax compliance can be defined as the degree to which a taxpayer complies or fails to comply with the tax laws and regulations of a country that can be expressed by declaring income, filing a return and paying a tax due promptly (Pratomo, 2018). Instances of tax noncompliance include failure to pay the proper amount of tax due to non-filing, underreporting of tax due on tax returns and non-payment or late payment of taxes owed (Abdul-Jabbar, 2019).

On average, about 30 percent of all taxpayers fail to submit their annual returns to the Ghana Revenue Authority (GRA), and many each year face prosecution for failing to file complete returns (GRA, 2018). Even though the GRA has progressively been carrying out audits on registered tax agents and corporation to unearth under-declaration, these audits have contributed less than 10 percent of the total tax collected by GRA. Despite the successes in terms of tax compliance, there are still implementation challenges with particular reference to registration, issuance of tax invoices, submission of accurate returns, keeping basic records of transactions for verification and prompt payment of tax due (Arhin, 2018; Saani, 2017).

The government of Ghana, through GRA had made efforts to strengthen tax compliance through a series of institutional reform among taxpayers coupled with the establishment of tax acts, appeal tribunal, and tax verification number (Saani, 2017). These interventions were put in place to address the challenge of poor tax revenue collection, which is mostly blamed on tax noncompliance by taxpayers and none remittance of taxes collected by corporate bodies due to poor accounting record-keeping. According to Arhin (2018), the total amount of tax payable in any economy is highly dependent on the levels of accounting record-keeping practices exhibited by organisations. Low levels of accounting record-keeping can contribute to tax noncompliance by taxpayers. This means, for SMEs to improve their tax compliance, there is a need for them to improve and maintain their accurate accounting record-keeping culture.

The discussion so far shows that taxation is one of the major sources of revenue to governments. The SME sector has great potential in contributing significantly to the country's revenue basket. However, in spite of the tax 
revenue potentials of the sector, Saani (2017) reported that the level of tax compliance of the SME sector in Ghana is less than 50 percent despite the compulsory nature of taxation as stipulated by various government legislations. This may be due to the perceived under-reporting and poor record-keeping cultures associated with SMEs. For example, some SMEs intentionally pay their employees very low basic salary, but huge allowances that are nontaxable (Saani, 2017). This phenomenon to a large extent affects the revenue basket of the state since income tax is calculated on the basic salary.

Furthermore, the emphasis of tax compliance research in Ghana has been on Value Added Tax (VAT) compliance to the neglect of research on income tax compliance and accounting record-keeping challenges (Agbadi, 2011; Saani, 2017). Unfortunately, research interest in the area within the SME sector of Ghana has been scanty, especially in a developing community like the Sekondi-Takoradi Metropolis (STM) in the Western Region of Ghana. It is against this backdrop that this study aimed at investigating the influence of accounting recordkeeping practices and other factors on tax compliance in the SME sector of Ghana, focusing on STM.

\subsection{Objectives of the study}

The purpose of the study was to investigate accounting record-keeping practices and tax compliance of SMEs, focusing on selected SMEs in STM in the Western Region of Ghana. The specific objectives of the study were to:

1. Examine the accounting record-keeping practices of SMEs in STM.

2. Determine SME owners/managers' attitudes toward tax compliance.

3. Examine the influence of accounting record-keeping practices on tax compliance of SMEs.

\subsection{Significance of the study}

The findings that will emerge from this study will guide tax practitioners and consultants to fashion out expert advice that is most suitable and appropriate for their clients to prevent them from breaking the tax laws. Owners/managers of SMEs will also benefit from the alternative tax compliance strategy that would be recommended to improve the operations of their businesses, particularly in the areas of good record-keeping and tax education. Furthermore, the findings will be used to identify tax compliance problems of SMEs and to improve the tax laws and procedures accordingly. Hence, it helps to improve tax compliance and reduce the tax compliance costs of the taxpayers and administrative costs of GRA. Also, the findings will serve as a guide to help GRA in reviewing its education programme by undertaking accounting record-keeping programmes as key parts to improve the quality of reporting by SMEs in the economy.

\subsection{Delimitation}

The study focused on accounting record-keeping and tax compliance, focusing on SMEs in STM. This means the findings of this study may not be a true representation of the tax compliance behaviour of all SMEs in Ghana. In relation to respondents, the study was delimited to owners/managers of SMEs and the two zonal heads of DTRD. The study focused on income, value-added, and corporate taxes that SMEs pay on behalf of the employees and the enterprise.

\section{Conceptual framework}

Accounting record-keeping practices, as revealed by extant literature, is of paramount importance to the success of every business. Most organisations are indifferent to proper accounting record-keeping, without which the effective determination of the firms' income cannot be ascertained. However, most extant works of literature were of the opinion that the primary objective of firms' accounting record-keeping was tax compliance-related. As an emerging area in the records management process, information on accounting record-keeping practices are indispensable and critical in an enterprise's continued survival. For that matter, records require content, structure and context to provide reliable evidence for effective tax compliance.

The independent variables were accounting record-keeping practices, sanctions and cooperation, staff attitude, and staff motivational postures. However, the dependent variable was tax compliance of SMEs. The framework for the study is illustrated in Figure 1. The study argues that accounting record-keeping practices of SMEs have a meaningful influence on SMEs tax compliance. However, other determinants such as sanctions and cooperation, staff attitude, and staff motivational postures when considered can either help in reducing the influence of accounting record-keeping practices or boost it to influence tax compliance of SMEs significantly. This means the influence accounting record-keeping practices have on tax compliance becomes much stronger when sanctions and cooperation, staff attitude and motivational postures are considered in the model or factored in the operation of SMEs. 


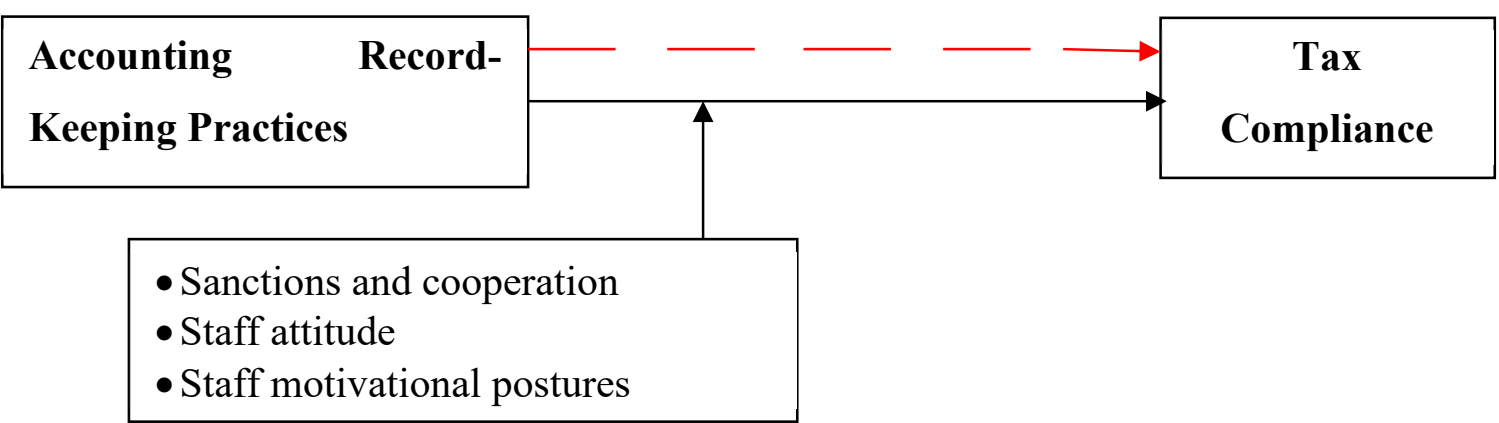

Figure 1: Accounting record-keeping practices and tax compliance of SMEs in STM Source: Author's construct, 2019

\section{Research methods}

The business fraternity is moving towards research-based practices to improve business standards. Many novice researchers are in a dilemma to adopt research design to explore reality through their research endeavour because of a tug of war on ontological, epistemological and axiological perspectives among quantitative and qualitative researchers (Creswell, 2014). In this confounding situation, this study adopted the concurrent triangulation mixed methods design to fuse both quantitative and qualitative standpoints of exploring reality.

\subsection{Population}

The population of the study consisted of eight strata of registered SMEs grouped into various associations recognised by the National Board for Small Scale Industries (NBSSI) in STM (NBSSI, 2018), and the zonal heads of the Domestic Tax Revenue Division (DTRD) within the region. The associations were categorised into eight sectors based on the nature of their operations. These groups are the Ghana Hairdressers and Beauticians Association, Ghana National Tailors and Dressmakers Association, Upholstery and Furniture Association, Ghana Electronic Servicing Technicians, Ghana Union of Professional Photographers, Wood Workers Association of Ghana, Ghana National Associations of Garages, and National Refrigerators and Air Condition Repairs. All the owners/managers of these businesses form the target population. According to the NBSSI (2018), there are 895 registered and active SMEs in the metropolis as of December 2018. The study looked at the views of the owners/managers of these SMEs and the two zonal heads of DTRD within the region regarding the issues raised by the study.

\subsection{Sample and sampling procedure}

Most researchers (Creswell, 2014; Kelly, 2016) are of the view that the most used acceptable approach for determining a sample in a survey is to specify the precision of estimation desired and then to determine the sample necessary to ensure it. As a result, a sample of 279 was obtained using Slovin's (as cited in White, 2015) recommended formula below, which was deemed appropriate, for the study. The formula is $\mathrm{n}=\mathrm{N} \div\left[1+\mathrm{N}\left(\mathrm{e}^{2}\right)\right]$, where $\mathrm{n}$ is the sample size, $\mathrm{N}$ is the population size, and $\mathrm{e}$ is the level of precision.

$$
\mathrm{n}=895 \div\left[1+895(0.05)^{2}\right]=895 \div 3.2375=276.45 \approx 277
$$

The sample comprised of 277 owners/managers of SMEs and two (2) zonal heads of DTRD. The two zonal heads were selected purposively for the interview. They were selected because the study was interested in their views since they relatively have more and better knowledge regarding tax compliance of SMEs in the metropolis. Also, they were selected because of the managerial role they play in the tax administration system. In addition, the study employed the stratified random sampling procedure to select the respondents (owners/managers of SMEs). Specifically, after grouping them into nine strata, simple random sampling technique that makes use of the lottery method was used to select the respondents.

\subsection{Data collection instruments, procedures and process}

The study was designed in such a way that it allowed for the use of multiple sources of primary data collection. The primary data were collected through field survey and interviews using questionnaire and an interview guide. The Cronbach alpha reliability coefficient obtained from the questionnaire was 0.857 , which was considered reliable (Kelly, 2016). The process of data collection was planned concurrently as shown in Figure 2 . The data collection process was planned in such a way that the various stages were fed into each other and allowed for simultaneous data collection procedure and analysis for purposes of data triangulation. 


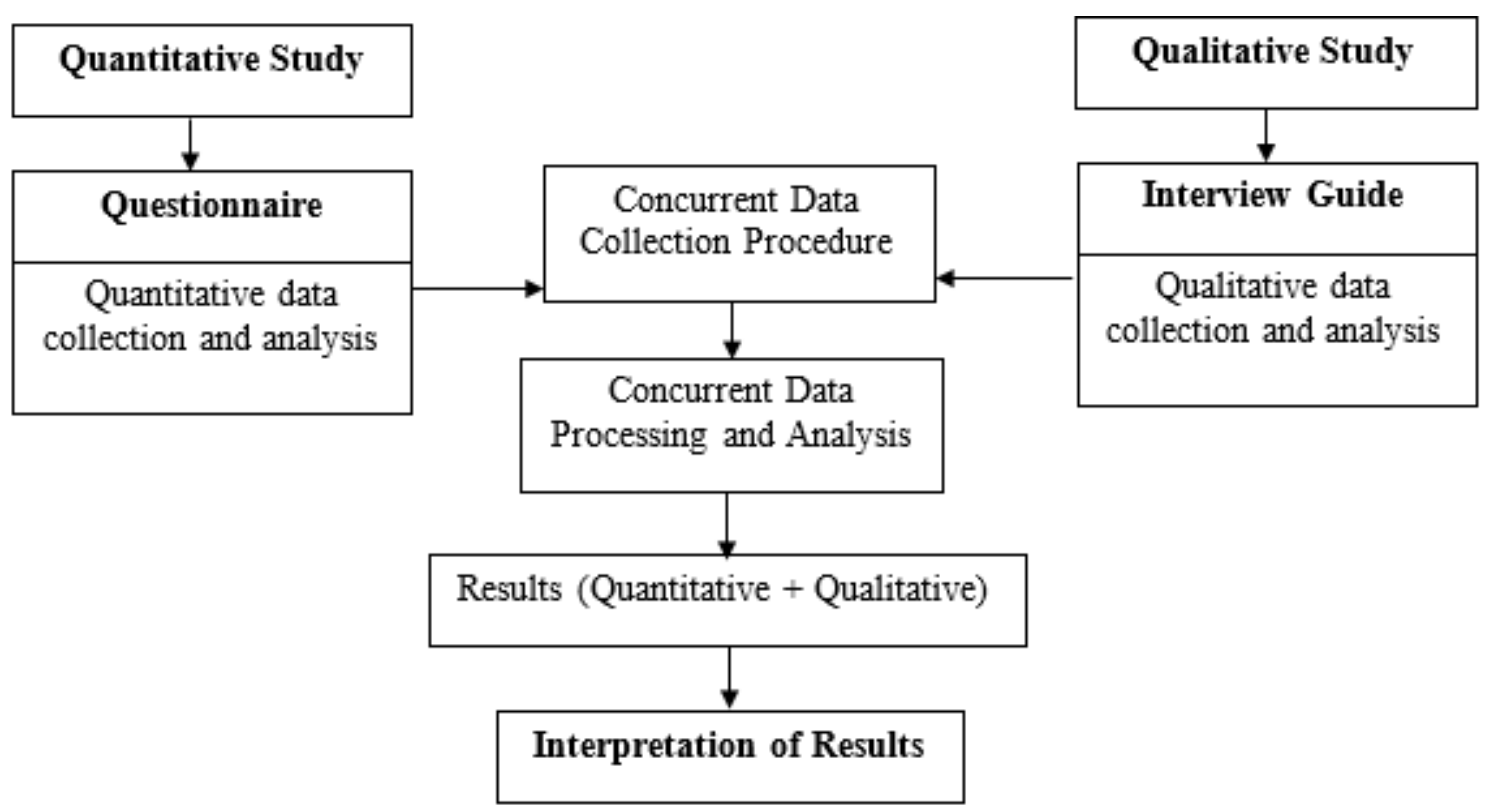

Figure 2: Data collection process

A period of eight weeks was used to collect the data. The questionnaires were administered by the researcher personally to the respondents with the support of eight field assistants who had adequate experience regarding data collection process. The eight field assistants were given training and orientation regarding the study, which made it easier for them to administer the questionnaires. The data collection procedures were carried out in three stages. The first stage was the collection of a list of respondents and participants. The second stage was the distribution of the questionnaires and the interviews conducted while the third stage focused on retrieving the questionnaires administered. The questionnaires were administered based on the lottery method of random sampling technique as indicated earlier. At the end of data collection, the researcher was able to collect completed and accurate data from 269 subjects. In the case of the questionnaire, 267 completed questionnaires administered were retrieved, resulting in 96.4 percent response rate. In the case of the interview, all the participants were interviewed.

\subsection{Data analysis}

The quantitative data were sorted and coded based on the procedures within the variable view of the statistical analysis software tool known as the Predictive Analytic Software (PASW) Version 21.0. The quantitative data were analysed using both descriptive and inferential statistical tools. Data on the first and second specific objectives were analysed using mean and standard deviation. Linear multiple regression analysis was used to analyse data regarding the third specific objective. The rationale for using these statistical tools was that the variables were all measured numerically using a unilinear scale to categorise the responses. In relation to the qualitative data, the axial coding system was used to analyse the data. This was done manually based on the objectives. After transcribing the data, the researcher sifted and sorted them based on the key issues and themes that were derived from the objectives. This helped in creating familiarity with the data in the mind of the researcher to facilitate the process of analysis.

\section{Results and discussion}

The first specific objective examined the accounting record-keeping practices of SMEs in STM. The study adopted mathematical approximation techniques to interpret the mean scores. The views of the respondents are presented in Table 1. The owners/ managers of SMEs disagreed that record-keeping practices are inclusive in their firm's management policies (Mean $=1.72, \mathrm{SD}=0.89$ ) and also good accounting record-keeping practices is one of the financial control systems of the firms (Mean $=1.64, \mathrm{SD}=1.01$ ). Also, respondents disagreed that as part of their culture, the firms practice good record-keeping to provide appropriate information regarding profit and loss to owners $($ Mean $=1.79, \mathrm{SD}=1.13)$, and keep accounting records to help track debtors and creditors (Mean = $1.52, \mathrm{SD}=1.10)$ 
Table 1: Respondents view on accounting record-keeping practices of SMEs in STM

\begin{tabular}{lcc}
\hline Statements on accounting record-keeping practices & Mean & SD \\
\hline $\begin{array}{l}\text { Record-keeping practices are inclusive in the firm's management policies } \\
\text { There are documentations in this firm to show that accounting records have been created or }\end{array}$ & 1.72 & 0.89 \\
received & 1.13 & 0.93 \\
Good accounting record-keeping practices is one of the financial control systems of the firm & 1.64 & 1.01 \\
For effective tax compliance, my firm ensures that accurate accounting records are kept and & & \\
made accessible to tax officials & 1.91 & 1.00 \\
As part of its culture, the firm practices good record-keeping in order to provide appropriate & & 1.79 \\
information regarding profit and loss to owners & 1.52 & 1.13 \\
The firm keeps accounting records in order to help track debtors and creditors. & 1.35 & 0.86 \\
The firm protects its records from dangers like fire, rainwater, rodents, etc. & 1.71 & 0.87 \\
Employees of the firm are aware of the regulations governing electronic accounting records & &
\end{tabular}
Source: Field Data, $2019 \quad$ Where SD = Standard Deviation $\quad(\mathrm{N}=267)$

In addition, respondents disagreed strongly that employees of the firms are aware of the regulations governing electronic accounting records (Mean $=1.71, \mathrm{SD}=0.87$ ). Respondents strongly disagreed that there are documentations in the firms to show that accounting records have been created or received $(\mathrm{Mean}=1.13, \mathrm{SD}=$ 0.93). Also, respondents disagreed that for effective tax compliance, the firms ensure that accurate accounting records are kept and made accessible to tax officials (Mean $=1.91, \mathrm{SD}=1.00$ ). Again, respondents strongly disagreed that firms protect their records from dangers like fire, rainwater, rodents, etc. (Mean $=1.35, \mathrm{SD}=0.86$ ). In all, the results show that the accounting record-keeping practices of SMEs in STM are negatively perceived by the respondents.

The views of the respondents are incongruent with Section five (5) of the tax law (Act 546) which makes it obligatory for service providers to register for VAT irrespective of turnover and to keep appropriate accounting records for that purpose (Saani, 2017). The above finding confirms that of the two zonal heads of the DTRD in charge of the metropolis, who also said that, a great number of SMEs in the metropolis do not maintain up to date accounting and other business records. One of the zonal heads further stated that some SMEs intentionally understate their record either to avoid tax or pay less, especially regarding income tax of staff.

The two zonal heads interviewed both indicated that the inspection/monitoring teams within the metropolis occasionally visit the various SMEs to examine and verify accounting records of SMEs during each financial year. However, for this financial year 2018/2019, they are yet to visit all of them because most of the SMEs have not yet submitted their returns and the authority is currently auditing tax returns that have been submitted. It is after the audit that the inspection teams will pay the default SMEs a visit to find answers to the queries raised.

One of the zonal heads said that most SMEs in the metropolis do not exhibit a significant level of professionalism in their accounting record-keeping practices because they do not follow lay down standards and principles. For effective tax compliance, these record-keeping practices are relevant and must be done professionally. Nevertheless, those with accurate records, some of the SMEs do not readily make these records accessible to us (tax officers). I think they usually design two records, one for tax officers and the other for owners.

The findings that emerged show that accounting record-keeping practices are not essential to owners/managers of SMEs, as a result, are perceived negatively. The findings are incongruent with the comments of Abdul-Jabbar (2019) who posits that the importance of proper record-keeping to SMEs cannot be underestimated. Keeping proper books of accounts enables SMEs to have accurate information on which to base decisions. They project purchase and sales, determine break-even point, and make a wide range of other financial analysis based on accounting information. According to Abdul-Jabbar, record-keeping has become the foundation on which the totality of modern business depends. Specifically, proper record-keeping by SMEs help to avert business failure, helps management in making sound decisions, helps in financial management and control, helps to facilitate the prompt filing of tax returns to regulatory or tax collecting government agencies etc.

The second specific objective determined owners/managers' attitudes toward tax compliance. Issues analysed include justice in the tax system, positive peer attitude and understanding of the tax laws. Other issues analysed were paying of tax fines and penalties, positive government image and lower compliance cost. The results are presented in Table 2. As presented in Table 2, respondents were of the view that justice in the tax system can influence their decision to comply with the country's tax law requirements (Mean $=3.25, \mathrm{SD}=0.88$ ). This means that owners/managers of SMEs consider justice in the tax system as a factor that can influence their decision to comply. This finding supports the assertion that taxpayers' perceptions of the procedural justice of the tax system, how the tax administration treats them and other similarly situated taxpayers, affect the legitimacy that taxpayers attribute to the administration, which in turn affects taxpayers' levels of compliance (Saani, 2017).

Also, respondents view positive peer attitudes as a factor that can influence them to comply with the tax laws (Mean $=3.38, \mathrm{SD}=0.91)$. This finding confirms that of Bhattarai and Koirala (2017) who posit that taxpayers may still commit non-compliance so long as this non-compliance is consistent with in-group expectations and 
norms. Also, respondents were of the view that understanding of the tax laws could improve their tax compliance behaviour (Mean $=3.45, \mathrm{SD}=0.90$ ). It is clear, therefore, that understanding of the tax laws plays an instrumental role in the tax compliance decision of most owners/managers of the various SMEs in STM. The findings support the views of Saani (2017) who posits that complexity in tax laws has come to be recognised as a possible reason for tax noncompliance.

Table 2: SME owners/managers' attitudes toward tax compliance in STM

\begin{tabular}{lcc}
\hline Statements on staff attitude toward tax compliance & Mean & Standard Deviation \\
\hline Justice in the tax system & 3.25 & 0.88 \\
Positive peer attitude & 3.38 & 0.91 \\
Understanding of the tax laws & 3.45 & 0.90 \\
Paying tax fines and penalties & 3.64 & 0.81 \\
Rewarding taxpayers & 3.18 & 0.93 \\
Degree of being detected for non-payment of tax & 2.23 & 0.87 \\
Positive government image & 3.73 & 0.91 \\
Aggressive enforcement efforts by tax authorities & 2.18 & 0.91 \\
Ethics and morality & 3.45 & 0.89 \\
Lower compliance cost & 2.91 & 0.99 \\
Mean of all means & 3.14 & 0.74 \\
\hline Source: Field Data, 2019 & & $(\mathrm{N}=267)$
\end{tabular}

Furthermore, respondents strongly agreed that tax fines and penalties can influence them to comply with the tax laws (Mean $=3.64, \mathrm{SD}=0.81$ ). These findings indicate that paying tax fines and penalties can affect positively the decision of SMEs to comply with the tax laws. This result supports the submissions made by Agbadi (2011) who posits that severity of sanctions has significant effects on tax compliance behaviour of firms. Even though respondents agreed that paying tax fines and penalties can influence their tax compliance, they also indicated that rewarding taxpayers can influence their decision to comply with the tax law requirements positively $($ Mean $=3.18$, $\mathrm{SD}=0.93$ ). This shows that genuinely rewarding taxpayers in an exchange relationship can increase tax compliance. With regard to the degree of being detected for non-payment of tax, respondents cannot be influenced to comply for fear of being detected for non-payment of tax $($ Mean $=2.23, \mathrm{SD}=0.87)$. This finding does not, however, support the conclusion drawn by Witte and Woodbury (2015). Witte and Woodbury in their study of small proprietors were of the view that there is a significant positive relationship between the risk of tax audit and the rate of voluntary tax compliance.

Furthermore, respondents strongly agreed that positive government image can influence their tax compliance behaviour positively (Mean $=3.73, \mathrm{SD}=0.91)$. This means owners/ managers of SMEs in STM can be influenced positively in terms of their tax compliance behaviour if the reputation and credibility of the government is increased. The results further show that employing aggressive enforcement efforts by tax authorities to ensure compliance in the $\mathrm{SME}$ sector may not be a successful strategy $(\mathrm{Mean}=2.18, \mathrm{SD}=0.91)$. Also, respondents believe that ethics and morality can have an influence on their decision to comply with the tax laws (Mean $=3.45, \mathrm{SD}=0.89$ ). Similarly, lower compliance cost can influence owners/managers of SMEs decision to comply with the tax law requirements $($ Mean $=2.91, \mathrm{SD}=0.99)$. In all, the result shows that owners/managers of SMEs in STM have a positive attitude toward tax compliance $($ Mean $=3.14, \mathrm{SD}=0.74)$. The finding that ethics and morality, and high compliance cost could affect the compliance levels of owners/managers of SMEs in STM confirm the study by Abdul-Jabbar (2019) which assert that high compliance costs, which may be due to complex tax schedules and rules, not only tilt the 'cost-benefit analysis' towards evasion but may also generate resentment, weakening taxpayers' moral conscience or even prompting them to evade as a form of 'punishment' for the tax administration.

The rationale of the last specific objective was to examine the influence of accounting record-keeping practices on tax compliance of SMEs in STM. In tackling this objective, the study employed multiple regression analysis. However, the study first checked for multicollinearity. After establishing that the contribution of the independent variables on the dependent variable largely was not as a result of multicollinearity problem, the study went further to examine the influence of accounting record-keeping practices, staff attitude toward tax compliance, sanctions and cooperation, and motivational postures on tax compliance using linear multiple regression analysis. The results are presented in Tables 3 . 
Table 3: Influence of accounting record-keeping practices and other variables on tax compliance of SMEs in STM

\begin{tabular}{|c|c|c|c|c|c|c|}
\hline \multirow[b]{2}{*}{ Variables } & \multicolumn{2}{|c|}{$\begin{array}{c}\text { Unstandardised } \\
\text { Coefficient }\end{array}$} & \multirow{2}{*}{$\begin{array}{c}\begin{array}{c}\text { Standardised } \\
\text { Coefficient }\end{array} \\
\text { Beta }(\beta)\end{array}$} & \multirow[b]{2}{*}{ Sig. } & \multicolumn{2}{|c|}{$\begin{array}{c}\text { Collinearity } \\
\text { Statistics }\end{array}$} \\
\hline & $\mathrm{B}$ & Std. Error & & & Tolerance & VIF \\
\hline Accounting record-keeping practices & 0.283 & 0.022 & $0.278^{* *}$ & 0.000 & 0.627 & 1.595 \\
\hline Staff attitude toward tax compliance & 0.098 & 0.022 & $0.111^{* *}$ & 0.000 & 0.481 & 2.079 \\
\hline Sanctions and cooperation & 0.111 & 0.026 & $0.098^{* *}$ & 0.000 & 0.574 & 1.743 \\
\hline Motivational postures & 0.066 & 0.021 & $0.072^{*}$ & 0.021 & 0.609 & 1.642 \\
\hline Constant & & & 1.464 & & & \\
\hline $\mathrm{R}$ & & & 0.711 & & & \\
\hline R Square & & & 0.593 & & & \\
\hline Adjusted R Square & & & 0.571 & & & \\
\hline
\end{tabular}

Source: Field Data, $2019 * \mathrm{p}<0.05, * * \mathrm{p}<0.01 \quad(\mathrm{~N}=267)$

Dependent Variable: Tax compliance

As depicted in Table 3, in order of importance, the independent variables that influenced tax compliance positively were accounting record-keeping practices $(\beta=0.278, \mathrm{p}<0.01)$, staff attitude toward tax compliance $(\beta$ $=0.111, \mathrm{p}<0.01)$, sanctions and cooperation $(\beta=0.098, \mathrm{p}<0.01)$, and motivational postures $(\beta=0.072, \mathrm{p}<$ $0.05)$. It is however significant to observe that the total contribution of the independent variables to the variance in the dependent variable is 0.593 with an adjusted $\mathrm{R}^{2}$ of 0.571 . This means that accounting record-keeping practices, staff attitude toward tax compliance, sanctions and cooperation, and motivational postures are able to explain 59.3 percent of the variance in tax compliance of SMEs in STM.

The findings from the quantitative data are inconsistent with the views of the two zonal heads interviewed. They both indicated that SMEs in the metropolis do not comply significantly to the tax laws. However, in relation to income tax, they sometimes under-state the fact by assigning large chunk of salary to allowances with a small basic salary. As a result, their employees' income tax and pension contribution are relatively small since these deductions are made on the basic salary. Again, both two zonal heads were of the view that accounting recordkeeping practices play a major role in tax compliance of SMEs in their catchment areas. They further stated that SME owners/managers' attitude toward tax compliance, sanctions and cooperation and motivational postures of taxpayers are also some of the factors that influence the tax compliance level of SME owners/managers in their catchment area.

The findings that emerged from Tables 3 and also the views of the two zonal heads show that accounting record-keeping practices are one of the major factors that help to improve tax compliance levels of SMEs. The findings corroborate with the assertion of Saani (2017) who posits that most SMEs are not interested in recordkeeping due to poor accounting and tax knowledge, which to a large extent affect their tax compliance negatively. Some SMEs view record-keeping as burdensome and, therefore do not consider it as an integral part of their business. Furthermore, the findings corroborate with the findings derived from Pratomo's (2018) study. Pratomo's (2018) study found that persuasion and enforcement, inadequate human resources, poor data management and lack of coordination are some of the factors that lead to tax non-compliance. The discussion so far shows that accounting record-keeping is one of the important elements of running a successful business, especially when it comes to tax compliance. Arhin's (2018) study concluded that record-keeping practices have a significant positive influence on tax compliance in the hospitality industry just like other industries.

\section{Conclusions}

Based on the key findings, the following conclusions can be drawn. First, SMEs in STM have a poor level of tax compliance which may be as a result of poor accounting record-keeping culture. With regard to SME owners/managers' attitude toward tax compliance, the study concludes that justice in the tax system, positive peer attitude and understanding of the tax laws are some of the attitudinal factors that influence them to comply with the tax law requirements. In addition, paying tax fines and penalties, positive government image and lower compliance cost are able to influence SME owners/managers' decision to comply with the tax law requirements. The accounting record-keeping practices of SMEs can help to improve their tax compliance levels. Thus, an improvement in the record-keeping practice of SMEs will lead to higher compliance with tax obligations which will ensure long term survival of the businesses.

\section{Recommendations}

It is recommended to the zonal heads of DTRD within the region that to improve the compliance level of SMEs, as part of their education programmes, should undertake record-keeping programmes to enhance the quality of 
reporting by SMEs. The programmes should primarily be education initiatives that seek to improve business practices and to increase tax compliance by encouraging more complete and comprehensive record-keeping practices by SMEs. The zonal heads should further promote the benefits to be obtained from good accounting record-keeping practices and consider introducing additional education programmes such as public workshops on maintaining books and records keeping.

\section{References}

Abdul-Jabbar, H. (2019). Income tax non-compliance of small and medium enterprises in Malaysia: Determinants and tax compliance costs. Unpublished doctoral thesis, Curtin Business School, School of Economics and Finance, Curtin University of Technology.

Agbadi, S. B. (2011). Determinants of tax compliance: a case study of VAT flat rate scheme traders in the Accra metropolis. Unpublished master's dissertation, Kwame Nkrumah University of Science and Technology, Kumasi.

Arhin, E. Y. (2018). Accounting record-keeping and tax compliance in the hospitality industry in Ghana. International Journal of Research in Business Management, 6(2), 39-56.

Bhattarai, I., \& Koirala, G. P. (2017). Taxation in Nepal with tax planning and VAT. Nepal, Kathmandu: Asmita Prakashan.

Creswell, J. W. (2014). Research design: Qualitative, quantitative, and mixed methods approaches (4 ${ }^{\text {th }}$ ed.). Califonia: Sage publications.

Ghana Revenue Authority (GRA, 2018). Annual report: Final draft. Unpublished report, GRA, Sekondi.

Kelly, A. P. (2016). Social research methods. London: University of London.

National Board for Small Scale Industries (NBSSI, 2018). Making SMEs more productive. Accra: NBSSI.

Pratomo, M. H. (2018). Investigating tax compliance risks of large businesses in Indonesia. Unpublished master's thesis, School of Graduate School of Business and Law, College of Business, RMIT University.

Saani, A-J. (2017). Promoting sustainable tax compliance in the small and medium scale sector in Accra, Ghana. IUG Journal of Humanities and Social Sciences, 2(1), 40-54.

White, C. J. (2015). Research: A practical guide (2 ${ }^{\text {nd }}$ ed.). Pretoria: Ithuthuko Investments Publishing.

Witte, A. D., \& Woodbury, D. F. (2015). The effect of tax laws and tax administration on tax compliance. National Tax Journal, 58(2), 1-13. 